\title{
\#MAGER: Aktivitas fisik ditinjau dari fear of missing out dan trait self- control pengguna Instagram
}

\author{
Audita Izza Balqis $^{(1)}$, Cleoputri Yusainy ${ }^{(2)}$ \\ (1), (2) Jurusan Psikologi, Universitas Brawijaya, Malang, Indonesia
}

In the world we live in today, technology has greatly simplified human life but at the same time significantly reduced physical activities. In this research, we examined the extent to which physical activity among 479 Instagram's users $\left(M_{\text {age }}=21.24, S D_{\text {age }}=1.31\right)$ could be predicted by fear of missing out (FoMO), a pervasive apprehension to stay connected virtually with others while accounting for the unique contribution of individual differences in controlling mental processes and behaviour (trait self-control). As predicted, participants with higher levels of FoMO more than those with lower levels of FoMo reported less adherence in carrying out physical activity. However, the role of FoMO on physical activity became insignificant once trait self-control was taken into account. Individuals with high self-control traits were able to display adequate physical activity, irrespective of their low or high levels of FoMO. This finding implies that the benefit of having good self-control in physical activity surpasses the detrimental role of FoMO. Given the importance of social media in shaping their life especially during the COVID19 pandemic, social media users need to be more selective in maintaining virtual friendships and balancing it with self-control exercises.

Keywords: fear of missing out (FoMO), Instagram users, physical activity, trait self-control

Era teknologi saat ini di satu sisi sangat mempermudah hidup manusia, namun di sisi lain mengurangi porsi gerakan tubuh dengan sangat signifikan. Dengan mempertimbangkan kontribusi unik perbedaan kemampuan individual dalam mengendalikan proses mental dan perilaku (trait self-control), penelitian ini bertujuan untuk menguji sejauh mana aktivitas fisik di kalangan pengguna media sosial Instagram dapat diprediksi oleh fear of missing out (FoMO) sebagai bentuk kecemasan spesifik akibat keinginan untuk terus terhubung secara virtual. Partisipan berjumlah $479\left(M_{\text {usia }}=21.24, S D_{\text {usia }}=1.31\right)$ yang direkrut melalui survei online yang dirancang sebagai studi korelasional. Hasil penelitan menunjukkan bahwa partisipan dengan FoMO yang lebih tinggi dibandingkan dengan partisipan dengan FoMO rendah melaporkan kepatuhan yang lebih rendah dalam menjalankan aktivitas fisik. Meskipun demikian, peran FoMO menjadi tidak signifikan ketika trait self-control partisipan diperhitungkan. Terlepas dari derajat FoMO mereka, individu-individu dengan trait self-control yang tinggi mampu menampilkan aktivitas fisik yang adekuat. Temuan ini berimplikasi bahwa peran positif trait selfcontrol melampui peran negatif FoMO dalam aktivitas fisik individu. Mengingat pentingnya peran interaksi virtual dalam memengaruhi kehidupan mereka terutama pasca status pandemi COVID-19, pengguna media sosial perlu lebih selektif dalam memilih pertemanan dan menyeimbangkannya dengan latihan self-control.

Kata kunci: aktivitas fisik, fear of missing out (FoMO), pengguna Instagram, trait self-control

MEDIAPSI, 2021, Vol. 7(2), 130-140, DOI: https://doi.org/10.21776/ub.mps.2021.007.02.5

Received: 09-03-2021. Revised: 10-08-2021. Accepted: 11-11-2021. Published online: 25-12-2021

Handling Editor: Ziadatul Hikmiah, Universitas Brawijaya, Malang, Indonesia.

*Corresponding author: Cleoputri Yusainy, Jurusan Psikologi, Universitas Brawijaya, Malang, Indonesia. E-mail: cleo.yusainy@ub.ac.id

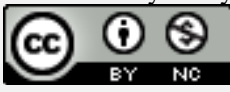

This work is licensed under a Creative Commons Attribution-NonCommercial 4.0 International License.

How to cite this article in accordance with the American Psychological Association (APA) $7^{\text {th }}$ guidelines:

Balqis, A. I., \& Yusainy, C. (2021). \#MAGER: Aktivitas fisik ditinjau dari fear of missing out dan trait self-control pengguna Instagram. MEDIAPSI, 7(2), 130-140. https://doi.org/10.21776/ub.mps.2021.007.02.5 


\section{Pendahuluan}

Gerak, baik secara biologis maupun fisik merupakan kebutuhan agar sistem kehidupan selalu terjaga dalam kondisi prima. Rekomendasi yang diterbitkan oleh World Health Organization (WHO, 2010) menyebutkan bahwa bagi individu-individu kelompok usia 18 - 64 tahun, aktivitas fisik yang dianjurkan untuk mereka mencakup kegiatan rekreasi, transportasi (berjalan atau bersepeda), okupasional, tugas rumah tangga, bermain, olahraga, dan latihan yang terencana dalam konteks aktivitas harian, keluarga, dan komunitas. Definisi "aktivitas fisik yang cukup" didasarkan pada panduan dari WHO (2010), yaitu "dalam satu minggu melakukan aktivitas aerobik intensitas sedang (misalnya, berenang dan berjalan santai) setidaknya selama 150 menit, atau melakukan aktivitas aerobik dengan intensitas tinggi (misalnya, bersepeda, bela diri, berlari) setidaknya selama 75 menit, atau kombinasi antara aktivitas aerobik intensitas sedang dan intensitas tinggi.

Berdasarkan rekomendasi tersebut, Kementerian Kesehatan Republik Indonesia (2018) mencatat bahwa sebesar $33.5 \%$ masyarakat Indonesia kurang melibatkan diri dalam aktivitas fisik. Dalam hal ini, dipastikan ada harga yang harus dibayar, atau dalam artian ada konsekuensi yang harus dipenuhi. Salah satunya adalah kesehatan. Jenis-jenis penyakit tidak menular yang berasosiasi dengan kurangnya aktivitas fisik merentang mulai dari kanker, ginjal kronis, stroke, hipertensi, dan diabetes mellitus (Kementerian Kesehatan Republik Indonesia, 2018). Sebaliknya, aktivitas fisik yang adekuat tidak saja dapat melindungi individu dari beragam penyakit namun bermanfaat pula untuk meningkatkan kesehatan mental dan fisiknya (WHO, 2010).
Penelitian sebelumnya menemukan bahwa aktivitas fisik terkait dengan kebutuhan psikologis dasar berupa kebutuhan otonomi, kompetensi, dan relasi (Ryan dkk., 2009). Ditinjau dari selfdetermination theory (Deci \& Ryan, 1985), ketiga kebutuhan dasar ini menjadi dasar pelibatan individu dalam aktivitas fisik. Sebagai konsekuensinya, kurangnya aktivitas fisik berpotensi untuk menimbulkan defisit dalam pemenuhan kebutuhan dasar tersebut. Defisit inilah yang kemudian memicu beragam upaya kompensasi seperti melalui media sosial. Peranan media sosial mentransformasi cara manusia berinteraksi. Di masa lalu, suatu pertemuan harus dilakukan secara tatap muka. Saat ini, aktivitas pertemuan tergantikan dengan perangkat yang semakin terjangkau. Media sosial memungkinkan individu tetap terafiliasi dengan orang lain, membangun kompetensi sosial, dan memperkuat ikatan sosial tanpa memerlukan perpindahan fisik (Przyblylski dkk., 2013). Hal ini berpotensi mengurangi porsi aktivitas fisik penguna media sosial.

Kajian literatur mengenai media sosial mengungkapkan bahwa kemampuan untuk mengkonstruksi proses sosial yang serupa dengan "dunia nyata" membawa implikasi bahwa interaksi virtual menjadi sama pentingnya dengan interaksi fisik, sekaligus sebagai perpanjangan dari "diri". Lebih dari itu, karakteristik utama media sosial adalah dinamika relasi yang terkoneksi secara rapat dan padat. Di media sosial, pengguna bebas memilih siapa yang ingin mereka jadikan teman ("friending") atau mereka ikuti ("follow").

Pengguna media sosial juga bisa sewaktu-waktu memberikan umpan balik terhadap konten yang ia sukai ("like", 
"love", atau "comment") atau sebaliknya. Matriks pertemanan di media sosial ini menjadi aturan main terkini yang merepresentasikan popularitas atau kesuksesan sosial penggunanya, berbeda dengan interaksi di dunia nyata yang seringkali bersifat lebih ambigu dan tergantung pada interpretasi masing-masing individu (Firth dkk., 2019). Kondisi ini dapat meningkatkan bentuk kecemasan spesifik akibat dorongan untuk terus terkoneksi pada aktivitas yang orang lain lakukan, yang dikenal dengan sebutan fear of missing out (FoMO: Przyblylski dkk., 2013). Individu mengalami FoMO ketika ia mengetahui orang lain memiliki pengalaman berharga atau menyenangkan, sementara ia tidak mengalaminya atau tidak ikut serta di dalamnya (Przyblylski dkk., 2013; Reagle, 2015).

Franchina dkk. (2018) menemukan bahwa FoMO merupakan prediktor bagi penggunaan media sosial secara eksesif dan tidak sehat serta perilaku terus-menerus mengakses media sosial tanpa memedulikan orang lain yang secara fisik hadir di hadapannya ("phubbing", phone snubbing). Dalam konteks akademik, FoMO memiliki asosiasi dengan minimnya motivasi belajar, lemahnya penyesuaian diri terhadap kehidupan kampus, serta kurangnya penguasaan materi pembelajaran (Alt \& Boniel-Nissim, 2018). Dalam riset ini, Peneliti berasumsi bahwa di kalangan pengguna Instagram, keberadaan FoMO dapat memprediksi kurangnya aktivitas fisik yang dilakukan oleh individu. Sifat dari media sosial seperti Instagram cenderung memiliki bias positif sebagai konsekuensi dari fitur memoles konten untuk memamerkan kesempurnaan (Lup dkk., 2015), yang memperbesar peluang terjadinya
FoMO. Hal ini juga ditunjang oleh sifat media sosial yang memudahkan akses untuk mengetahui aktivitas yang orang lain lakukan, beli, atau perbincangkan, yang selanjutnya menimbulkan potensi pengguna untuk merasa kehilangan atau tertinggal dari hal-hal yang menyenangkan atau bermanfaat bagi mereka (Przyblylski dkk., 2013).

Di sisi lain, dalam konteks aktivitas fisik, penelitian Yusainy dkk. (2019) di kalangan mahasiswa di Indonesia menemukan bahwa kepatuhan yang lebih tinggi diprediksi oleh perbedaan individual dalam trait self-control. Trait self-control merujuk pada kemampuan individu secara sadar dalam mengelola perilaku dan proses mental untuk menyesuaikan standar yang telah individu tersebut tetapkan (Tangney dkk., 2004). Sebagaimana digambarkan dalam model cybernetic, self-control mencakup empat mekanisme feedback loops, yaitu TOTE (Test-Operate-Test-Exit). Testing merupakan fase saat diri subjek dibandingkan dengan standar tertentu.. Konflik antar diri subjek dan standar yang dimaksud menjadi isyarat bahwa fase Operations harus dilakukan yang bertujuan mengubah elemen perilaku dan proses mentalnya. Selanjutnya pada fase Testing, individu melakukan evaluasi dengan tujuan mengetahui apakah diri individu tersebut telah menyesuaikan standar. Berikutnya individu memasuki fase Exit apabila tidak diperlukan upaya lain untuk mereduksi konflik yang terjadi. Dari penjelasan ini, terlihat bahwa aktivasi self-control membutuhkan afek negatif sebagai sinyal bahwa individu perlu menampilkan respons untuk meredakan ketidaknyamanan akibat stimulus tertentu (Yusainy, 2017). Namun karena individu-individu dengan self-control yang tinggi lebih terfokus pada sasaran 
jangka panjang daripada pemenuhan kebutuhan sesaat yang bersifat kontraproduktif, mereka terhindar dari beragam perilaku maladaptif (Hagger dkk., 2019). Hal ini secara teoretis menjelaskan bahwa meskipun kecemasan yang berakar pada FoMO dapat memprediksi rendahnya aktivitas fisik, kecemasan ini lebih terkelola pada individu dengan kapasitas self-control yang baik tanpa mengorbankan kepatuhannya dalam melakukan aktivitas fisik.

Secara keseluruhan, penelitian ini bertujuan untuk mengetahui sejauh mana FoMO dapat memprediksi aktivitas fisik (Hipotesis 1), serta memetakan kontribusi trait self-control dalam aktivitas fisik setelah memperhitungkan peran FoMO (Hipotesis 2) pada pengguna Instagram. Riset ini difokuskan pada pengguna media sosial Instagram. Data global per Januari 2020 menunjukkan bahwa pengguna Instagram di Indonesia berjumlah 63 juta dan menempati peringkat ke-4 dunia ("Leading countries based on Instagram audience size as of October 2021", 2021). Di sisi lain, trait selfcontrol adalah kualitas inheren yang dapat dilatih secara mandiri melalui beragam latihan sederhana (Baumeister dkk., 2006).

\section{Metode}

\section{Partisipan dan desain penelitian}

Partisipan adalah mahasiswa S-1 pengguna Instagram sejumlah 479 orang, yang direkrut melalui media sosial dengan metode nonrandom sampling untuk mengikuti survei online. Dari total 741 orang yang mengakses pranala survei, diperoleh data lengkap 479 partisipan $(27.77 \%$ lakilaki) dengan rerata usia 21.24 tahun $(S D=$ 1.31, rentang usia 18 sampai 29 tahun). Mayoritas partisipan memiliki lebih dari 300 akun pengikut di Instagram (follower: 80.3\%), mengikuti lebih dari 300 akun di Instagram (following: 70.36\%), dan mengakses Instagram lebih dari 30 menit per hari dalam dalam dua minggu terakhir (68.69\%). Sementara itu, 58.25\% partisipan melakukan aktivitas fisik di waktu luang (leasure-time physical activity) seperti lari, bersepeda, futsal, basket, dan berenang dengan rerata 2.33 hari per minggu $(S D=$ 1.69). Proporsi ini lebih rendah dibandingkan eksperimen Chan dkk. (2020) yang menemukan bahwa leasure-time physical activity dilakukan oleh sebanyak $70.30 \%$ partisipan mahasiswa Indonesia.

\section{Prosedur dan pengukuran}

Izin untuk menyelenggarakan penelitian ini diperoleh dari komite etik lokal. Setelah membaca informasi mengenai survei, menyatakan persetujuan, dan mengisi data demografis, partisipan dihadapkan pada kuesioner untuk mengukur aktivitas fisik (Self-Reported Adherence Scale for Physical Activity [SRAS-PA]; Yusainy dkk., 2019), trait self-control (Brief Self-Control Scale [SCS]; Tangney dkk., 2004), dan fear of missing out (Fear of Missing Out Scale [FoMOS]; Przybylski dkk., 2013). Selain itu, partisipan diminta menginformasikan jumlah akun Instagram yang mengikuti partisipan (follower), jumlah akun Instagram yang partisipan ikuti (following), dan lama waktu rerata yang digunakan untuk mengakses Instagram dalam dua minggu terakhir. Debrief mengenai tujuan penelitian diberikan pada bagian penutup survei, disertai opsi undian untuk memeroleh insentif pulsa total Rp 200.000 untuk empat partisipan.

Self-Reported Adherence Scale for Physical Activity (SRAS-PA) versi bahasa 
Indonesia diambil dari Yusainy dkk. (2019; lihat juga Chan dkk., 2020), yang merupakan modifikasi dari Chan dan Hagger (2012) untuk mengukur kepatuhan perilaku aktivitas fisik dalam dua minggu terakhir. Partisipan memberikan nilai dalam pernyataan mengenai frekuensi melakukan aktivitas fisik yang cukup dan pernyataan mengenai usaha untuk melakukan aktivitas fisik yang cukup. Dalam penelitian ini diperoleh skor rerata SRAS-PA $=3.50(S D=1.52)$ dengan nilai reliabilitas yang memadai $(\alpha=.82)$.

Brief Self-Control Scale (SCS) untuk mengukur trait self-control diadaptasi dari Tangney dkk. (2004) ke dalam bahasa Indonesia oleh Yusainy (2017). SCS mengukur kapasitas partisipan dalam mengendalikan pikiran, emosi, dan impuls serta meregulasi performa dan mengubah kebiasaan sehari-hari (contoh butir pertanyaan: "Saya menolak hal-hal yang buruk bagi saya"). Rerata skor SCS yang tinggi menunjukkan trait self-control yang tinggi. Partisipan dalam penelitian ini melaporkan skor rerata SCS sebesar 3.08 $(S D=0.48)$, dengan nilai reliabilitas $\alpha=.77$. Fear of Missing Out Scale (FoMOS) untuk mengukur tingkat FoMO. Skala ini diadaptasi dan dimodifikasi dari Przybylski dkk. (2013) dan Reagle (2015) ke dalam bahasa Indonesia oleh Triani (2017) untuk menggambarkan perasaan gelisah yang muncul ketika tertinggal suatu pengalaman peristiwa menarik yang sedang dialami oleh teman, ketika teman mengetahui informasi yang lebih menarik, atau ketika teman memiliki sesuatu yang lebih baik. Nilai rerata FoMOS partisipan dalam penelitian ini adalah $2.43(S D=0.64)$, dengan nilai reliabilitas yang sangat memadai $(\alpha=.88)$.

Data hasil penelitian diolah dengan menggunakan analisis regresi hierarki, untuk menguji hipotesis bahwa aktivitas fisik merupakan fungsi dari FoMO (Hipotesis 1) dan hipotesis bahwa trait self-control berkontribusi memprediksi aktivitas fisik setelah memperhitungkan peran FoMO (Hipotesis 2).

\section{Hasil}

Profil partisipan berdasarkan jenis kelamin ditampilkan pada Tabel 1. Tidak ada perbedaan antarjenis kelamin dalam hal $(t=$ $0.064, p=.949)$ dan trait self-control $(t=-$ $0.721, p=.471)$, tetapi partisipan perempuan melaporkan aktivitas fisik yang lebih rendah dibandingkan partispan laki-laki $(t[477]=$ 4.004. $p<0.001)$. FoMO memiliki asosiasi positif dengan jumlah follower, jumlah following, dan lama waktu mengakses Instagram ( $p s<.001$ ). Tidak ada korelasi antara usia partisipan dengan variabelvariabel yang menjadi fokus riset ini ( $p s>$ .223). Data jenis kelamin, jumlah follower, jumlah following, dan lama waktu mengakses Instagram dikontrol dalam analisis selanjutnya. 
Tabel 1. Profil Partisipan Berdasarkan Jenis Kelamin $(N=479)$.

\begin{tabular}{lccc}
\hline \multicolumn{1}{c}{ Data } & Perempuan & Laki-laki & Total \\
& & & \\
\hline Usia $(M ; S D)$ & $21.176(1.321)$ & $21.414(1.274)$ & $21.24(1.311)$ \\
Jumlah follower $>$ 300 $(\%)$ & 81.242 & 78.195 & $80.4 \%$ \\
Jumlah following $>300(\%)$ & 72.212 & 65.414 & $70.4 \%$ \\
Lama akses Instagram $>30$ & 69.653 & 66.165 & $68.7 \%$ \\
menit per hari $(30 \%)$ & & & \\
FoMOS $(M ; S D)$ & $2.430(0.600)$ & $2.426(0.721)$ & $2.430(0.635)$ \\
Brief SCS $(M ; S D)$ & $3.090(0.473)$ & $3.054(0.053)$ & $3.080(0.481)$ \\
SRAS-PA $(M ; S D)$ & $3.327(1.427)$ & $3.936(1.650)$ & $3.496(1.515)$ \\
\hline Keterangan. $M=$ rata-rata. SD = deviasi standar. Brief SCS = Brief Self-Control Scale. FoMOS = Fear of Missing Out Scale. SRAS-PA $=$ \\
Self-Reported Adherence Scale for Physical Activity.
\end{tabular}

Tabel 2. Analisis Regresi Hierarki Aktivitas Fisik dengan Prediktor FoMO dan Trait SelfControl $(N=479)$.

\begin{tabular}{|c|c|c|c|c|c|c|}
\hline Kriterium & Step & Prediktor & $\Delta R^{2}$ & Total $R^{2}$ & $\beta$ & $p$ \\
\hline $\begin{array}{l}\text { SRAS- } \\
\text { PA }\end{array}$ & 1 & $\begin{array}{l}\text { Jenis kelamin; jumlah } \\
\text { follower; jumlah following; } \\
\text { lama akses Instagram }\end{array}$ & .03 & .03 & $\begin{array}{c}-.62 * * * \\
-.01 \\
.03 \\
-.011\end{array}$ & .003 \\
\hline & 2 & FoMOS & .02 & .05 & $-.33 * *$ & .005 \\
\hline & 3 & Brief SCS & .05 & .10 & $.72 * * *$ & $<.001$ \\
\hline
\end{tabular}

Keterangan. Brief SCS $=$ Brief Self-Control Scale. FoMOS $=$ Fear of Missing Out Scale. SRAS-PA $=$ Self-Reported Adherence Scale for Physical Activity. $\mathrm{R}=$ Koefisien regresi berganda. $\beta=$ koefisien regresi terstandarisasi untuk masing-masing prediktor. Coding: $1=$ laki-laki; $2=$ perempuan.

$* * p<.01 ; * * * p<.001$.

Pada analisis regresi hierarki (Tabel 2), data demografis berupa jenis kelamin partisipan beserta jumlah follower, jumlah following, dan lama waktu mengakses Instagram yang dimasukkan sebagai prediktor pada Step 1 mampu memprediksi sebagian kecil varians dalam aktivitas fisik $\left(\Delta R^{2}=.03\right)$. Skor FoMO yang dimasukkan pada Step 2 memberikan sumbangan varians yang terjelaskan sebesar .02 dengan kekuatan prediksi $R^{2}$ yang meningkat menjadi 5\% (Hipotesis 1). Skor trait self-control yang dimasukkan pada Step 3 meningkatkan penjelasan varians dalam aktivitas fisik sebesar .05 dengan penambahan kekuatan prediksi $R^{2}$ menjadi hampir $10 \%$ (Hipotesis 2). Hal ini menunjukkan trait self-control berkontribusi secara signifikan dalam menambah daya varians dalam memprediksi aktivitas fisik. Pada model final ini, kepatuhan yang lebih tinggi dalam melakukan aktivitas fisik diprediksi oleh jenis kelamin laki-laki $(\beta=-0.65, t=$ 
$-4.36, p<.001)$ serta trait self-control yang lebih tinggi $(\beta=0.72, t=5.110, p<$ .001), sedangkan peran FoMO menjadi tidak signifikan $(p>.081)$, demikian pula dengan peran jumlah follower, jumlah following, dan lama waktu mengakses Instagram ( $p s>.442)$.

\section{Diskusi}

Penelitian ini menguji sejauh mana aktivitas fisik di kalangan pengguna media sosial Instagram dapat dipetakan melalui FoMO dan trait self-control. Studi di bidang neurosains menunjukkan bahwa FoMO berasosiasi dengan aktivasi area otak yang menangani atensi kepada orang lain serta kebutuhan akan penerimaan sosial (Lai dkk., 2016). Konsekuensinya, atensi individu yang mengalami FoMO lebih ditujukan untuk tetap terkoneksi dengan orang lain daripada untuk melakukan aktivitas lain yang bersifat nonsosial. Sesuai hipotesis awal, partisipan dalam penelitian ini lebih patuh dalam menjalankan aktivitas fisik yang cukup ketika derajat FoMO yang ia laporkan semakin rendah. Hasil ini melengkapi penelitian sebelumnya mengenai kaitan FoMO dengan penggunaan media sosial secara berlebihan (Franchina dkk., 2018), problem dalam konteks akademik (Alth \& Boniel-Nissim, 2018), dan keselamatan berkendara (Przyblylski dkk., 2013).

Jika ditinjau kembali dari selfdetermination theory (Deci \& Ryan, 1985), perilaku individu didasari oleh beragam tipe motivasi yang berada pada kontinum otonomi. Motivasi yang bersifat otonom akan terbentuk ketika perilaku yang ditampilkan dianggap memiliki nilai positif dan berharga, dianggap sebagai bagian dari diri sehingga terkait dengan nilai dan perilaku lain dalam berbagai MEDIAPSI | 2021, Vol. 7, No. 2, 130-140 domain kehidupan individu, serta sematamata bersumber dari kesenangan, minat, dan kepuasan yang diperoleh dari ditampilkannya perilaku tersebut (Ryan dkk., 2009). Dalam konteks aktivitas fisik, kultivasi motivasi yang bersifat otonom dapat diperkuat oleh keberadaan tingginya trait self-control (Yusainy dkk., 2019). Trait self-control yang tinggi pada individu memiliki keyakinan dan intensi yang kuat untuk berpartisipasi dalam perilaku yang mengarah pada kesehatan, serta cenderung mewujudkan intensi ini ke dalam perilaku konkret (Hagger dkk., 2019). Hal ini menjelaskan temuan penelitian ini bahwa meskipun FoMO memprediksi aktivitas fisik yang lebih rendah, prediksi ini melemah ketika trait self-control dimasukkan sebagai prediktor. Peran trait self-control sebagai prediktor kepatuhan yang lebih tinggi dalam aktivitas fisik berada di atas peran FoMO, bahkan melampaui peran jenis kelamin partisipan.

Di sisi lain, eksperimen Dogan (2019) mencatat bahwa individu dengan konstruk diri yang saling tergantung (biasanya berasosiasi dengan orientasi budaya kolektivistis) lebih rentan mengalami FoMO. Dari perspektif selfconstrual theory (Markus \& Kitayama, 1991), ketika seseorang memandang orang lain sebagai bagian dari dirinya maka keinginan untuk terus terlibat dalam pengalaman dan kegiatan orang lain akan muncul secara alamiah. Rereta jumlah follower dan following partisipan dalam penelitian ini adalah lebih dari 300 akun pengguna Instagram lain; jumlah ini berasosiasi dengan FoMO yang semakin tinggi. Walaupun individu yang mengalami FoMO terdorong untuk menampilkan berbagai aktivitas di media 
sosial dalam rangka mencukupi kebutuhan dasar akan otonomi, kompetensi, dan relasi (Przybylski dkk., 2013), aktivitas yang dipilih (misalnya, pertemanan secara eksesif) tidak serta-merta akan memuaskan kebutuhan tersebut. Melalui karya seminalnya, Dunbar (1992) menyatakan bahwa secara kognitif otak manusia hanya mampu mempertahankan sekitar 150 pertemanan yang bersifat stabil. Instagram, seperti halnya Twitter dan Facebook memungkinkan terbentuknya jejaring sosial dalam jumlah yang masif dibandingkan relasi tatap muka, namun fluktuasi Dunbar's number konsisten pada kisaran 100-200 akun pertemanan saja yang mampu dikelola oleh penggunanya (Gonçalves dkk., 2011). Penelitian selanjutnya perlu mengkaji lebih jauh mengenai jumlah dan bentuk pertemanan seperti apa di media sosial yang mampu memenuhi kebutuhan dasar individu yang mengalami FoMO, utamanya dalam hal otonomi.

Keterbatasan utama penelitian ini bersumber pada desain korelasional, sehingga tidak dapat ditarik simpulan sebab-akibat antara prediktor dengan aktivitas fisik sebagai variabel kriterium. Relasi sebaliknya mungkin terjadi jika individu menampilkan aktivitas fisik rendah, sehingga FoMO yang ia alami meningkat dan trait self-control yang ia miliki menurun. Aktivitas fisik menjadi faktor risiko yang bisa dimodifikasi untuk mengatasi beragam penyakit termasuk gangguan mental (Belair dkk., 2018). Penelitian selanjutnya dengan desain eksperimental perlu dilakukan untuk membandingkan kelompok yang melakukan aktivitas fisik cukup vs. tidak cukup untuk dilihat pengaruhnya terhadap FoMO dan trait self-control pengguna MEDIAPSI | 2021, Vol. 7, No. 2, 130-140 media sosial. Keterbatasan lain adalah penggunaan partisipan mahasiswa dengan pengukuran FoMO pada level kecenderungan perilaku (trait-like). Kompleksitas FoMO perlu diteliti lebih jauh dalam konteks populasi yang memiliki predisposisi patologis seperti kesepian, depresi, kecemasan sosial, serta preferensi untuk menggunakan komunikasi online dibandingkan komunikasi fisik (lihat Wegmann dkk., 2017).

\section{Kesimpulan}

Sebagai solusi yang diharapkan dapat memberikan manfaat, penelitian ini memetakan sejauh mana trait self-control memprediksi varians dalam aktivitas fisik setelah memperhitungkan derajat fear of missing out (FoMO) pada pengguna Instagram. Peneliti menemukan bahwa meskipun kecemasan yang bersumber pada FoMO memprediksi aktivitas fisik yang lebih rendah, perbedaan individual dalam hal trait self-control dapat menjadi pengawal bagi kepatuhan individu tersebut dalam menjalankan aktivitas fisik. Perlu dikemukakan bahwa penelitian ini dilakukan sebelum bulan Maret 2020 saat status coronavirus (COVID-19) ditetapkan oleh WHO sebagai pandemi global, dengan dasar pemikiran bahwa keberadaan FoMO merupakan konsekuensi dari aturan main pertemanan di media sosial (Firth dkk., 2019). Pascastatus pandemi, dalam diskusi di media digital tersua bahwa kebijakan berupa pembatasan fisik dan sosial berpotensi untuk meningkatkan FoMO karena interaksi virtual saat ini tidak sekadar merefleksikan kesuksesan pengguna media sosial namun telah beroperasi pada level fungsi survival secara sosial (Fernandez \& Matt 2020; Rutledge, 2020). Latihan self-control 
melalui aktivitas non-digital sederhana seperti memperbaiki postur tubuh saat sedang duduk atau berjalan dan menghindari kata-kata makian (Baumeister dkk., 2006) adalah cara yang bisa ditempuh secara mandiri untuk mengendalikan agar kehadiran FoMO dalam situasi apapun tidak sampai merugikan kesehatan mental dan fisik pengguna media sosial.

\section{Daftar Pustaka}

Alt, D., \& Boniel-Nissim, M. (2018). Links between adolescents' deep and surface learning approaches, problematic Internet use, and fear of missing out (FoMO). Internet Interventions, 13, 3039. https://doi.org/10.1016/j.invent. 2018.05.002

Baumeister, R. F., Gailliot, M., DeWall, C. N., \& Oaten, M. (2006). Selfregulation and personality: How interventions increase regulatory success, and how depletion moderates the effects of traits on behavior. Journal of Personality, 74(6), 1773-1801. https://doi.org/10.1111/j.14676494.2006.00428.x

Belair, M-A., Kohen, D. E., Kingsbury, M., \& Colman, I. (2018). Relationship between leisure time physical activity, sedentary behaviour and symptoms of depression and anxiety: Evidence from a populationbased sample of Canadian adolescents. BMJ Open, 18. https://doi.org/10.1136/bmjopen2017-021119

Chan, D. K. C., \& Hagger, M. S. (2012). Trans-contextual development of motivation in sport injury prevention among elite athletes. Journal of Sport and Exercise Psychology, 34(5), 661-682. https://doi.org/10.1123/jsep.34.5.661

Chan, D. K., Stenling, A., Yusainy, C., Hikmiah, Z., Ivarsson, A., Hagger, M. S., ... \& Beauchamp, M. R. (2020). Editor's Choice: Consistency tendency and the theory of planned behavior: a randomized controlled crossover trial in a physical activity context. Psychology

Health, 35(6), 665-684. https://doi.org/10.1080/08870446.20 19.1677904

Deci, E. L., \& Ryan, R. M. (1985). Intrinsic motivation and selfdetermination in human behavior. Plenum.

Dogan, V. (2019). Why do people experience the fear of missing out (FoMO)? Exposing the link between the self and the FoMO through selfconstrual. Journal of Cross-Cultural Psychology, 50(4), 524-538. https://doi.org/10.1177/00220221198 39145

Dunbar, R. I. M. (1992). Neocortex size as a constraint on group size in primates. Journal of Human Evolution. 22(6), 469-493. https://doi.org/10.1016/00472484(92)90081-J

Fernandez, L., \& Matt, S. J. (2020, 7 April). Instead of FOMO, covid-19 demands we embrace JOMO - the joy of missing out. Washington Post. https://www.washingtonpost.com/ou tlook/2020/04/07/instead-fomocovid-19-demands-we-embracejomo-joy-missing-out/ 
Firth, J., Torous, J., Stubbs, B., Firth, J. A., Steiner, G. Z., Smith, L., .... Sarris, J. (2019). The "online brain": How the Internet may be changing our cognition. World Psychiatry, 18(2), 119-129. https://doi.org/10.1002/wps.20617

Franchina, V., Vanden Abeele, M., van Rooij, A. J., Lo Coco, G., \& De Marez, L. (2018). Fear of missing out as a predictor of problematic social media use and phubbing behavior among Flemish adolescents. International Journal of Environmental Research and Public Health, $\quad 15(10), \quad 2319$. https://doi.org/10.3390/ijerph151023 19

Gonçalves, B., Perra, N., Vespignani, A. (2011). Modeling users' activity on Twitter networks: Validation of Dunbar's number. PLOS One, 6(8): e22656. https://doi.org/10.1371/jour nal.pone. 0022656

Hagger, M. S., Hankonen, N., Kangro, E.M., Lintunen, T., Pagaduan, J., Polet, J., .. Hamilton, K. (2019). Trait self-control, social cognition constructs, and intentions: Correlational evidence for mediation and moderation effects in diverse health behaviors. Applied Psychology: Health and Well-Being, 11(3), 407-437. https://doi.org/10.1111/aphw.12153

Kementerian Kesehatan Republik Indonesia. (2018). Hasil utama RISKESDAS 2018 https://www.litbang.kemkes.go.id/ha sil-utama-riskesdas-2018

Lai, C., Altavilla, D., Ronconi, A., \& Aceto, P. (2016). Fear of missing out (FOMO) is associated with MEDIAPSI | 2021, Vol. 7, No. 2, 130-140 activation of the right middle temporal gyrus during inclusion social cue. Computers in Human Behavior, 61, 516-521. https://doi.org/10.1016/j.chb.2016.03 .072

Leading countries based on Instagram audience size as of October 2021. (2021, October). Statista.com. https://www.statista.com/statistics/57 8364/countries-with-most-instagramusers/

Lup, K., Trub, L., \& Rosenthal, L. (2015). Instagram \#instasad? Exploring associations among Instagram use, depressive symptoms, negative social comparison, and strangers followed. Cyberpsychology, Behavior, and Social Networking, 18 , 247-252. https://doi.org/10.1089/cyber.2014.0 560

Markus, H. R., \& Kitayama, S. (1991). Culture and the self: Implications for cognition, emotion, and motivation. Psychological Review, 98, 224-253. https://doi.org/10.1037/0033-

295X.98.2.224

Przybylski, A. K., Murayama, K., DeHaan, C. R., \& Gladwell, V. (2013). Motivational, emotional, and behavioral correlates of fear of missing out. Computers in Human Behavior, 29, 1841-1848. https://doi.org/10.1016/j.chb.2013.02 .014

Reagle, J. (2015). Following the Joneses: FOMO and conspicuous sociality. First Monday, 20(10). https://doi.org/10.5210/fm.v20i10.60 64

Rutledge, P. B. (2020, 23 Maret). Pandemic FoMO: How much news 
is too much? Psychology Today. https://www.psychologytoday.com/u s/blog/positively-

media/202003/pandemic-fomo-howmuch-news-is-too-much

Ryan, R. M., Williams, G. C., Patrick, H., \& Deci, E. L. (2009). Selfdetermination theory and physical activity: The dynamics of motivation in development and wellness. Hellenic Journal of Psychology, 6, 107-124.

https://doi.org/10.1186/1479-5868-978

Tangney, J., Baumeister, R. F., \& Boone, A. L. (2004). High self-control predicts good adjustment, less pathology, better grades, and interpersonal success. Journal of Personality, $\quad 72, \quad 271-324$. https://doi.org/10.1111/j.00223506.2004.00263.x

Triani, C. A. (2017). Hubungan antara kebutuhan berelasi dan fear of missing out pada pengguna media sosial dengan harga diri sebagai moderator [Tesis, Program Pascasarjana Universitas Gadjah Mada].

http://etd.repository.ugm.ac.id/peneli tian/detail/128543

Wegmann, E., Oberst, U., Stodt, B., ～\& Brand, M. (2017). Online-specific fear of missing out and internet-use expectancies contribute to symptoms of internet-communication disorder. Addictive Behaviors Reports, 5, 3342. https://doi.org/10.1016/j.abrep.20 17.04.001

World Health Organization. (2010). Global recommendations on physical activity for health. http://www.who.int/dietphysicalactiv ity/publications/9789241599979/en/

Yusainy, C. (2017). Feeling full or empty inside? Peran perbedaan individual dalam struktur pengalaman afektif. Jurnal Psikologi Fakultas Psikologi Universitas Gadjah Mada, 44(1), 117.

https://doi.org/10.22146/jpsi.7652

Yusainy, C., Chan, D. K. C., Hikmiah, Z., \& Anggono, C. O. (2019). Physical activity in Indonesian University students: The contradictory roles of dispositional mindfulness and selfcontrol. Psychology, Health \& Medicine, 24(4), 446-455. https://doi.org/10.1080/13548506.201 8.1546015 